\section{Evidence not practised: The underutilisation of preventive fissure sealants}

\author{
D. L. Bonetti'
}
IN BRIEF
- Suggests it is internationally recognised that dentists should take a more proactive approach to caries, using both preventive and restorative treatments.
- Reports that the application of fissure sealants is an evidence-based preventive treatment known to be globally underutilised in primary dental care.
- Stresses that for dentistry to progress via the preventive paradigm it is important to understand why it is underutilised.

International and UK professional organisations, Cochrane systematic reviews, and international and UK guidance documents all support the application of preventive fissure sealants (PFSs) as an effective treatment for reducing caries. However, PFSs are well known to be underutilised in primary care. This paper collates data from PFS-relevant studies in Scotland, which has a large population of children at caries risk, to identify the beliefs and factors dentists perceive as influencing their decision not to provide this treatment. This information provides a platform to suggest how to increase the application of PFSs in this region (a standardised audit incorporating evidence-based behaviour change techniques, supplemental guidance on how to implement gold-standard recommendations in practice, training). This may also be relevant outside of Scotland, as well as to the implementation of other evidence-based behaviours in practice.

\section{INTRODUCTION}

There should be no further debate about the clinical efficacy of fissure sealants for preventing and arresting dental decay in susceptible teeth and individuals. The body of supporting evidence is of the highest possible quality, including internationally recognised research papers and systematic reviews. ${ }^{1-3}$ Preventative fissure sealants (PFSs) are currently endorsed by international, as well as UK professional organisations, and recommended in international and UK dental guidance documents, taskforce action plans, and oral health promotion programmes. ${ }^{4-17}$ Every dental curriculum ensures that all dentists know what fissure sealants are, and how to apply them. Nevertheless, the continuing promotion of PFSs in many government programmes is testimony to this being internationally acknowledged as an evidence-based treatment persistently underutilised in practice.

Scotland is a case in point. For more than a decade, primary care dentists in Scotland have been specifically primed to understand the importance of this treatment in managing children. In 2000, the Scottish Intercollegiate Guideline Network published their guidance

Senior Research Fellow, Dental Health Services Research Unit, DDEC, Frankland Building, University of Dundee, Small's Wynd, Dundee, DD1 4HN

Correspondence to: Dr D. L. Bonetti

Email: d.I.bonetti@dundee.ac.uk; Tel: 01382381702

\section{Refereed Paper}

Accepted 12 December 2013

DOI: 10.1038/sj.bdj.2014.248

${ }^{\circledR}$ British Dental Journal 2014; 216: 409-413 encouraging the application of PFSs. ${ }^{10}$ In 2006, the Scottish Executive changed the dental fee structure to provide a direct fee for PFSs. In 2010, the Scottish Dental Clinical Effectiveness Programme published another guidance document recommending PFSs, specifically aimed at primary care dentists in Scotland. ${ }^{12}$ Sequential government administrations have each funded preventive oral health initiatives and programmes which include the application of PFSs. ${ }^{15}$

It is now obvious that government and professional recommendations, knowledge dissemination, as well as financial incentives, have all been ineffective as interventions to encourage the implementation of this treatment. The actual number of PFSs applied in Scotland has remained relatively unchanged since explicit PFS data was first collected in 2006, when 39,951 children received a PFS. ${ }^{20-21}$ In 2011, only 39,461 children received a PFS $^{21}$ (though the population did not remain the same). The total number of children in Scotland under 16 in 2006 was 854,000, the same number under 14 years of age in the 2011 census. ${ }^{20-21}$ Unfortunately, this deficit does not arise because preventive oral healthcare is no longer required by a healthier population. The latest epidemiological data suggests that most Scottish children are still at medium to high risk of developing dental caries. ${ }^{18-21}$ In recent national surveys, $42 \%$ of primary 1 children showed signs of dental decay and 50\% of primary 7 children had decay experience. Unquestionably, there remains a dire ethnographic need to address this issue.
With evidentiary, academic, professional and government support already in place, the challenge is to understand why PFSs remain an underutilised treatment in Scotland and what can be done to improve the situation. The author has been involved in a number of studies conducted in Scottish primary dental care during the period 2002 to 2013. These studies had different aims and designs, were carried out by different research teams and collaborators, and were variously funded by the Medical Research Council, the Chief Scientist Office, the Scottish Higher Education Funding Council, and NHS National Education for Scotland. Despite these differences, the unifying theme for these studies was the use of psychological models to understand knowledge translation (evidence to practice) in the dental setting. Also, in all of these studies, model components (beliefs) were assessed using theory-derived operationalisations, so assessments are consistent and replicable. Together these studies contain a great deal of data on the beliefs of primary care dentists in Scotland about evidence-based clinical practice, including the application of PFSs.

The aim of this paper is to see if this data can lead to suggestions for alternative approaches to encouraging PFS application in Scotland. It is hoped that this will also provide some insight into the issue elsewhere.

\section{STUDY SUMMARIES}

\section{PFS beliefs}

The Scottish Executive introduced a financial incentive to encourage primary care 
dentists in Scotland to place more PFSs following a nationally randomised controlled trial which presented evidence that specific remuneration would be more effective than more education. ${ }^{22}$ In this trial, all participating dentists, regardless of intervention group, completed a questionnaire assessing beliefs about applying PFSs. The aim of this questionnaire was to further a greater understanding of the decision to apply a PFS, should a financial incentive and/or education not succeed. The questionnaire assessed PFS knowledge (clinical and evidential) as well as beliefs, framed using a number of psychological models. A detailed description of these models, why they were chosen, and of the results, can be found in another published paper. ${ }^{23}$

In brief, the number of correct knowledge items did not relate to the number of PFSs applied. However, the number of PFSs dentists placed during the trial was associated with the following: their general intention to apply PFSs; whether they thought the benefits outweighed the costs (positive outcome expectancies and risk perceptions); if they had already given thought to fitting the application of PFSs into their usual management of child patients (action planning); and if they were already doing so many of them that not doing them took more thought (habit). These results suggested that influencing these beliefs may influence the application of PFSs. However, at the time there was no need to design this intervention, as the financial incentive intervention was successful in the trial. Why this effect was not more long-lasting at the service level will be discussed later in this paper.

\section{Mandatory assessment}

The next study with PFS-related material was an investigation of whether mandatory assessment, occurring only in Scotland during the vocational training year, better prepared dental trainees (VDPs) for their future careers. ${ }^{24-25}$ In consultation with 120 UK professional, educational and academic stakeholders, a questionnaire was developed assessing the beliefs and outcomes that the training year was meant to influence, regardless of region. Outcomes included confidence in performing clinical and non-clinical behaviours, as well as evidence-based decision-making, assessed via scenario. One of these scenarios was about the application of PFSs.

The questionnaire was distributed to all VDPs in Scotland, Wales and Northern Ireland, as well as to Northern and North Western Deaneries, immediately after graduation and at the end of the training year, every year for 5 years beginning 2003. The most detailed comparative analyses were performed for the first three cohorts, and included approximately $40 \%$ of all UK VDPs during that period.

The results suggested that these VDPs were extremely confident that they could apply a PFS if they wanted to (mean $=6.8$ out of a possible 7 ; standard deviation $=0.5$ ) . However, only 60\% actually elected to apply a PFS in the scenario where the evidencebased response was to place one. There was no significant difference between Scottish VDPs and VDPs from the rest of the UK in their general confidence about applying a PFS, or in the percentage who decided correctly. Variables which significantly differentiated VDPs who decided to apply a PFS from those that did not, were: intention to include PFSs in the general managing of caries; how important PFSs were perceived to be (attitude); and perceptions of how difficult they were to do (perceived behavioural control).

\section{Knowledge translation}

The next PFS-relevant study involved the development of a template questionnaire operationalising a number of psychological models, with the facility to incorporate different target behaviours to be predicted/ explained. This methodology aimed to explore the relative power and consistency of the models for furthering an understanding of knowledge translation within and across professions and clinical behaviours. Detailed descriptions of these models, why they were chosen and the study results can be found elsewhere. ${ }^{26-29}$ The application PFSs was one of the study's target behaviours.

Primary care dentists from across Scotland $(\mathrm{N}=29)$ were randomly selected to take part in semi-structured interviews asking about the factors and situations which might influence their decision to place a PFS when managing 6- to 16-year-old patients. The results of this qualitative study were then used to adapt the template psychology questionnaire, and this was then posted to randomly selected dentists $(\mathrm{N}=120)$ across Scottish health boards. ${ }^{27}$

This study found all models included variables significantly associated with the decision to apply a PFS. In terms of the primary aim of the overall study, this meant considerably more work was required before determining a 'best' model for knowledge translation. Nevertheless, the results are more informative for the purpose of this paper. Responses and comments to the postal questionnaire showed that the factors and situations identified in the qualitative study (Table 1) resonated with the much larger sample. Furthermore, the results suggested the main drivers of the decision to apply PFSs when taking these factors into account were
Table 1 Factors which may influence the decision to apply a preventive fissure sealant Factor

\begin{tabular}{|c|c|}
\hline \multicolumn{2}{|l|}{ Factor } \\
\hline \multirow{6}{*}{ Clinical } & Presence of clinically detectable caries \\
\hline & $\begin{array}{l}\text { Previous work done (unrestored } \\
\text { lesions/heavily restored/if there are } \\
\text { already sealants on } 6 s \text { ) }\end{array}$ \\
\hline & $\begin{array}{l}\text { Success of previous work (how long FS } \\
\text { is likely to last) }\end{array}$ \\
\hline & $\begin{array}{l}\text { Anatomical issues (fissure depth/size } \\
\text { of mouth) }\end{array}$ \\
\hline & Moisture control \\
\hline & Type of tooth (if 6 or 7 ) \\
\hline \multirow{10}{*}{ Patient } & Age \\
\hline & Attitude of parents \\
\hline & Anxiety \\
\hline & Cooperation (behaviour) \\
\hline & Attendance \\
\hline & Attitude to teeth \\
\hline & Oral hygiene \\
\hline & Sugar consumption \\
\hline & Family history of decay \\
\hline & If using fluoride toothpaste \\
\hline \multirow{5}{*}{ Dentist } & Perception of parental pressure \\
\hline & Time since last seen \\
\hline & Busy clinic \\
\hline & $\begin{array}{l}\text { Knowledge of patient (new or known } \\
\text { for a long time) }\end{array}$ \\
\hline & $\begin{array}{l}\text { Concern that an underlying active } \\
\text { lesion may progress undetected }\end{array}$ \\
\hline
\end{tabular}

attitude (how important PFSs were considered to be), outcome expectancies, and habit. Although these variables predicted scenario decision-making rather than actual practice, participants did not appear to be deciding in a 'socially desirable' way. In this survey, the correct decision was to apply a PFS in all six scenarios. Participating dentists decided to apply a PFS in two of the six scenarios on average, and this decision was not systematic, that is, different scenario situations prompted different dentists to apply a PFS. The questionnaire also assessed knowledge, which was not related to scenario decision, nor to the general intention to apply PFSs as part of managing this age group.

\section{TRiaDS}

The author is currently involved in an international collaboration to develop a theoretically informed framework for understanding knowledge translation that is transferable across international jurisdictions as well as professional disciplines. The collaboration's data on dental issues is generated through the core TRiaDS (translation 
Table 2 Theory-derived beliefs and domains associated with the decision to apply a preventive fissure sealant and possible behaviour change techniques

\begin{tabular}{|c|c|}
\hline Beliefs associated with PFS* & Evidence-based behaviour change techniques** \\
\hline \multirow[t]{3}{*}{ Intentiona } & $\begin{array}{l}\text { Prompt intention formation and goal setting } \\
\text { Encourage the person to decide to act or set a general goal }\end{array}$ \\
\hline & $\begin{array}{l}\text { Provide information about others' approval, pressure, support. } \\
\text { Information about what others think, will approve or disapprove of } \\
\text { behaviour change }\end{array}$ \\
\hline & $\begin{array}{l}\text { Provide general encouragement } \\
\text { Praising or rewarding the person for performance }\end{array}$ \\
\hline $\begin{array}{l}\text { Attitudea }^{a} \\
\text { Outcome expectancies } \\
\text { Risk perception }\end{array}$ & $\begin{array}{l}\text { Provide information on consequences } \\
\text { Information about the benefits or costs of action or inaction, focusing on } \\
\text { what may happen if the person does or does not do the behaviour }\end{array}$ \\
\hline $\begin{array}{l}\text { Perceived behavioural } \\
\text { control }^{3} \text { (perceived ability } \\
\text { to overcome difficulties } \\
\text { and perform behaviour) }\end{array}$ & $\begin{array}{l}\text { Modelling/demonstration of the behaviour } \\
\text { Provide an observable sample of the performance of the behaviour directly } \\
\text { in person or indirectly, for example via film, pictures for the person to aspire } \\
\text { to or imitate. } \\
\text { Behavioural practice/rehearsal } \\
\text { Prompt practice or rehearsal of the performance of the behaviour one or } \\
\text { more times in a context or at a time when the performance may not be } \\
\text { necessary, in order to increase habit and skill. }\end{array}$ \\
\hline Habitc & \multirow{2}{*}{$\begin{array}{l}\text { Action planning } \\
\text { Explicit statement of where, when, and how a behaviour will be performed. } \\
\text { Prompts/cues } \\
\text { Introduce or define environmental or social stimulus with the purpose of } \\
\text { prompting or cueing the behaviour. }\end{array}$} \\
\hline Action plans ${ }^{d}$ & \\
\hline 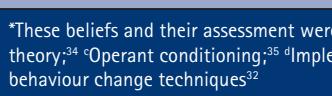 & $\begin{array}{l}\text { ng psychological models: :Theory of planned behaviour:33 }{ }^{3} \text { bocial cognitive } \\
\text { Illustrative definitions are from the Abraham and Michie taxonomy of }\end{array}$ \\
\hline
\end{tabular}

research in a dental setting) programme. ${ }^{30}$ This programme is now embedded in other national programmes of research and training in Scotland with the support of the Chief Dental Officer, the Postgraduate Dental Dean, and Chair of the National Dental Advisory Committee, with funding from NHS Education for Scotland.

Part of the TRiaDS remit is to investigate the impact of guidance documents and inform the development of interventions to increase that impact, if required. Six months after one guidance document, The Prevention and Management of Dental Caries in Children, was published, a random sample of dentists in Scotland were sent a questionnaire asking about current practice and beliefs relating to recommended practice (including PFSs). ${ }^{31}$ The results cannot be described in detail here because they are as yet unpublished. However, preliminary analyses reveal that responding dentists $(N=131)$ thought that PFSs were a very effective treatment, and $72 \%$ said they were highly motivated to place them. However, $75 \%$ acknowledged that they did not always follow guidance recommended PFS practice, nor did they intend to change that behaviour.

\section{DISCUSSION}

This paper presents information from a body of work asking primary care dentists in Scotland about their beliefs regarding the application of PFSs. Given that evidentiary, academic, professional and government support has failed to encourage greater PFS application in practice, the aim of this paper is to see if this data can inform suggestions about what else may be done to improve the situation in Scotland. It is hoped that this will also provide some insight into the issue elsewhere, as PFS underutilisation is an international problem.

A summary of theory-derived beliefs revealed in these studies as pertinent to applying PFSs, is presented in Table 2. It is acknowledged these beliefs were not assessed in every study, nor were these studies designed to evidence causation. However, these beliefs repeatedly showed a relationship with PFSs when they were assessed, which suggests that influencing them may be key to influencing this behaviour. This suggests that designing an intervention to influence these beliefs is one way to encourage primary care dentists in Scotland to apply more PFSs.

There are evidence-based psychological techniques that can be used to influence these beliefs (see Table 2), which provides the framework for an intervention. ${ }^{32}$ This population is required to perform audits as part of their NHS service agreement, which suggests a population-appropriate intervention format. An example of how to operationalise these techniques using this format would be: - Set the audit goal as increasing PFSs (target: intention; techniques: intention formation and goal setting)
- Include an introductory paragraph about evidentiary and professional support (targets: intention, attitude, outcome expectancies; techniques: provide information about others' approval, provide general encouragement to apply PFSs, provide information about consequences of not applying PFSs)

- Ask dentists to write out how they can increase PFSs in their practice and to follow set examples to do so, which will suggest how to deal with situations known to inhibit PFS application, derived from Table 1 (targets: perceived behavioural control, implementation intention, habit; techniques: action planning, modelling and rehearsal)

- Include a standardised data collection form to complete for a period of time (target: perceived behavioural control, habit; techniques: prompts, monitoring and rehearsal).

Explicitly describing how this proposed intervention is expected to change PFS behaviour should enable a clear understanding of why it succeeded or failed, thereby informing future investigations into PFS application. Given that most children are at risk of caries in Scotland, this intervention concentrates on simply increasing the number of PFSs. It could be adapted for dentists dealing with lower risk populations. The goal-setting could be used for more explicit definition of risk to identify when PFSs are appropriate/health-benefiting and the action planning examples could model situations that are regionally relevant.

Regardless of possible adaptions, the underlying expectation of this intervention is that it will help push dentists to apply a PFS in situations where they currently do not. However, an anecdotally supported insight from these studies is that dentists do not believe that they are departing from best practice when deciding not to apply a PFS. This decision is perceived to be a rational response to a pragmatic circumstance or an exceptional factor (see Table 1). Guidance documents and government programmes do not consider the influence of these salient factors and situations when recommending PFSs, and dentists do when deciding to place them. It is plausible to posit that this viewpoint is responsible for this evidence-based treatment not occurring more in practice. The gap between best and current PFS practice is unlikely to close without getting to grips with this fundamental issue.

The proposed intervention addresses this with action planning examples to suggest options for increasing PFSs when confronted with salient factors. However, there are 
limits to how many examples this intervention can have. Even if successful, intervention effects will be limited to dentists who experience it. Another method of reaching more dentists could be provided by new and revised guidelines including assistance on how to overcome likely barriers alongside each gold-standard recommendation. This supplemental guidance would reinforce the importance of each recommendation and of persisting in efforts to overcome these barriers, both evidence-based methods for influencing behaviour. Providing this guidance would thereby reduce inappropriate variations in practice, in these situations at least.

Another way of reaching more dentists is to teach dental trainees how to overcome likely barriers to implementing PFSs along with the mechanics of the treatment itself. In these studies, clinical and evidentiary PFS knowledge was never associated with the decision to apply a PFS. This suggests that knowledge of the procedure and its effectiveness is not enough to enable dentists to implement it in situations where they currently do not, or to enable them to recognise that sometimes decisions not to apply a PFS are based on their own mutable beliefs rather than the patient's actual health benefit.

It is possible that offering a higher financial incentive might encourage more PFs. However, introducing a fee in 2006 only increased the number FS placed in the very short term. It is plausible to suggest that the amount of the fee was not sufficient to affect the driving beliefs and factors that influence PFS decision-making. However, determining exactly how much of an increase in fee is needed to do this is likely to require a study with a larger sample of dentists (than in Scotland) to power it sufficiently. Furthermore, introducing a greater financial incentive for PFSs can send a false message that other treatments still included within general capitation are unimportant. Since these behaviours include tooth brushing and diet advice, it is possible that the resulting costs to children's oral health would outweigh the benefit of more PFSs. This suggests something other than a financial incentive intervention is required.

It is possible that more research or a systematic review including more studies will identify other beliefs and strategies that may be relevant. Nonetheless, these studies do provide a cohesive platform to suggest further actions which could be carried out to improve this situation in Scotland. While the studies discussed in this paper may be specific to Scotland, the issues they raise are not. There is no evidence to suggest that dentists in Scotland are less professional, caring, or evidence-based in their beliefs and practice than their UK and international colleagues. Scotland stands out because data on beliefs and performance are more easily accessible at this level of detail. It is highly likely that factors that inhibit PFS application in Scotland are synonymous with those inhibiting dentists elsewhere who also underutilise this evidence-based treatment. Designing interventions, guidelines and training to enable as many dentists as possible to recognise when clinical decisions are based on beliefs that can and should be changed (for example, motivation, attitude, perceived difficulty, perceived ineffectiveness), as well as enable them to deal with evidence-to-practice barriers, would benefit the implementation of all evidence-based treatments.

The list of colleagues who should be acknowledged for their significant contribution and expertise to the research described in this paper would be longer than the paper itself, so I hope they forgive a general thank you. I would also like to thank participating dentists who took part in this research, and the grant providers (the Medical Research Council, the Chief Scientist Office, the Scottish Higher Education Funding Council and NHS National Education for Scotland) who funded these studies. The views expressed in this paper are those of the author and may not be shared by others.

1. Locker D, Jokovic A, Ka E J. Prevention. Part 8: The use of pit and fissure sealants in preventing caries in the permanent dentition of children. Br Dent J 2003: 195: 375-378.

2. Mejàre I, Lingström $P$, Petersson $L G$, Holm A K , Twetman S, Källestål C, Nordenram G, Lagerlöf F, Söder B, Norlund A, Axelsson S, Dahlgren H. Cariespreventive effect of fissure sealants: a systematic review. Acta Odontol Scand 2003; 61: 321-330.

3. Ahovuo-Saloranta A, Hiiri A, Nordblad A, Mäkelä $M$, Worthington $H$ V. Pit and fissure sealants for preventing dental decay in the permanent teeth of children and adolescents. Cochrane Database Sys Rev 2008; CD001830.

4. Beauchamp J, Caufield P W, Crall J J et al. Evidencebased clinical recommendations for the use of pitandfissure sealants. A report of the American Dental Association Council on Scientific Affairs. J Am Dent Assoc 2008; 139: 257-268.

5. American Academy of Pediatrics. Recommendations for preventive paediatric oral health care. Pediatrics 2000; 105: 645-646.

6. Welbury R, Raadal M, Lygidakis N A. European Academy of Paediatric Dentistry. EAPD guidelines for the use of pit and fissure sealants. Eur J Paediatr Dent 2004; 5: 179-184.

7. Nunn J H, Murray J J, Smallridge J. British Society of Paediatric Dentistry. Fissure Sealants. Int J Paediatr Dent 2000; 10: 174-177.

8. American Academy for Paediatric Dentistry. Rationale and guidelines for pit and fissure sealants. Paediatric Dent 2005; 5: 89-90.

9. BASCD and Department of Health. Delivering Better Oral Health: An evidence-based toolkit for prevention. 2nd ed. London: DH, 2009.

10. Scottish Intercollegiate Guidelines Network. SIGN 47: Preventing dental caries in children at high caries risk: Targeted prevention of dental caries in the permanent teeth of 6-16 year olds presenting for dental care. Edinburgh: Scottish Intercollegiate Guidelines Network, 2000. Online guideline available at: www.sign.ac.uk/guidelines (accessed January 2014).

11. Scottish Intercollegiate Guidelines Network. SIGN 83: Prevention and management of dental decay in the pre-school child. Edinburgh: Scottish Intercollegiate Guidelines Network, 2005. Online guideline available at: www.sign.ac.uk/guidelines (accessed January 2014).

12. Scottish Dental Clinical Effectiveness Programme Guidance on the prevention and management of dental caries in children. Dundee: Scottish Dental Clinical Effectiveness Programme, 2010. Online information available at: www. SDCEP.org.uk (accessed January 2014).

13. Irish Oral Health Services Guideline Initiative. Pit and fissure sealants: evidence-based guidance on the use of sealants for the prevention and management of pit and fissure caries. Cork (Ireland): Oral Health Services Research Centre, 2010.

14. Lewis D W, Ismail A I. Periodic health examination: Prevention of dental caries. The Canadian Task Force on the Periodic Health Examination. CMAJ 1995; 152: 836-846.

15. Macpherson L, Ball G, Brewster L et al. Childsmile: the national oral health improvement programme in Scotland. Part 1: establishment and development. $\mathrm{Br}$ Dent J 2010; 209: 73-78.

16. Task Force on Community Preventive Services. Recommendations regarding selected interventions to prevent dental caries, oral and pharyngeal cancers, and sports-related craniofacial injury. Am J Prev Med. 2002; 23: 21-54.

17. Centres for Disease Control and Prevention (CDC). Recommendations for using fluoride to prevent and control dental caries in the United States. Online information available at: http://www.cdc.gov/mmwr preview/mmwrhtml/rr5014a1.htm (accessed January 2014).

18. National Dental Inspection Programme. Report of the 2012 detailed national dental inspection programme of primary 1 children and the basic inspection of primary 1 and primary 7 children. Information Services Division, 2012. Online report available at http://www.isdscotland.org/Health-Topics/ Dental-Care/Publications/2012-11-27/2012-11-27DentaINDIP-Report.pdf (accessed March 2014).

19. National Dental Inspection Programme of Scotland: Report of the 2008 Survey of P1 Children. Scottish Dental Epidemiological Coordinating Committee. Online report available at http://www.dundee.ac.uk/ dhsru/scottishdental/docs/ndip_scotland2008.pdf (accessed March 2014).

20. National Dental Inspection Programme of Scotland. Report of the 2011 detailed national dental inspection programme of primary 7 children and the basic inspection of primary 1 and primary 7 children. Online report available at http://www.dundee.ac.uk/ dhsru/scottishdental/docs/ndip_scotland2011.pdf (accessed March 2014).

21. NHS Scotland Information Services Division. Dental Care Publications. Online information available at www.isdscotland.org/Health-Topics/Dental-Care/ Publications (accessed April 2014).

22. Clarkson J E, Turner S, Grimshaw J M et al. Changing clinicians' behaviour: a randomized controlled trial of fees and education. J Dent Res 2008; 87: 640-644.

23. Bonetti $\mathrm{D}$, Johnston $\mathrm{M}$, Turner $\mathrm{S}$, Clarkson J. Applying multiple models to predict clinicians' behavioural intention and objective behaviour when managing children's teeth. Psychol Health 2009; 24: 843-860.

24. Scottish Dental Practice Based Research Network. Online information available at http://www.sdpbrn. org.uk/ (accessed March 2014).

25. Bonetti D, Young L, Rennie J, Clarkson J. Evaluating dental vocational training: How does Scotland compare to the rest of the UK? Br Dent J 2008; 204: 195-202

26. Bonetti $\mathrm{D}$, Pitts $\mathrm{N}$, Eccles M et al. Applying psychological theory to evidence-based clinical practice: identifying factors predictive of taking intra-oral radiographs. Soc Sci Med 2006; 63: 1889-1899.

27. Bonetti $D$, Johnston $M$, Clarkson J E et al. Applying psychological theories to evidence-based clinical practice: Identifying factors predictive of placing preventive fissure sealants. Implement Sci 2010; 5: 25 .

28. Grimshaw J, Eccles M, Steen N et al. Applying psychological theories to evidence-based clinical practice: Identifying factors predictive of lumbar spine xray for low back pain in UK primary care 
practice. Implement Sci 2011: 6: 55.

29. Eccles M, Grimshaw J, Johnston M et al. Applying psychological theories to evidence-based clinical practice: Identifying factors predictive of managing upper respiratory tract infections without antibiotics. Implement Sci 2007; 2: 26

30. Clarkson J E, Ramsay C R, Eccles M P et al. The translation research in a dental setting (TRiaDS) programme protocol. Implement Sci 2010; 5: 57.
31. Scottish Dental Clinical Effectiveness Programme Guidance on the Prevention and Management of Dental Caries in Children 2010. Online guidelines available at www.SDCEP.org.uk (accessed March 2014).

32. Abraham C, Michie S. A Taxonomy of Behaviour Change Techniques Used in Interventions. Health Psychol 2008; 27: 379-387.

33. Ajzen I. The theory of planned behaviour. Organ
Behav Hum Dec Processes 1991: 50: 179-211.

34. Bandura A. Health promotion from the perspective of social cognitive theory. Psychol Health 1998; 13: 623-649.

35. Blackman D. Operant conditioning: an experimental analysis of behaviour. London: Methuen, 1974.

36. Gollwitzer P M. Goal achievement: the role of intentions. In Stroebe W. Hewstone M (eds) European Review of Social Psychology. Chichester: Wiley, 1993. 